\title{
Proportionate Cancer Mortality in Methyl Methacrylate-Exposed Orthopedic Surgeons Compared to General Surgeons
}

\author{
James Henry Diaz
}

Published online: 29 January 2011

(C) American College of Medical Toxicology 2011

\begin{abstract}
Methyl methacrylate (MMA), a volatile liquid used to make dentures, hearing aids, joint prostheses, and medical adhesives, has been associated with colorectal carcinomas in acrylic sheet manufacturing workers. A casecontrol proportionate cancer mortality investigation was conducted to determine cancer death differences in orthopedic surgeons performing total joint replacements (TJRs) (MMA-exposed cases) and general surgeons not performing TJRs (unexposed controls). The American Colleges of Orthopedic Surgeons and General Surgeons provided complete demographic information on 468 male orthopedic surgeons and 1,890 male general surgeons who died during 1991-2001. Decedent data was submitted to the National Death Index for matching with underlying causes of death on state death certificates. Proportionate differences in ages at death, deaths from cancer, and deaths from site-specific cancers were analyzed for statistically significant differences by unpaired, two-tailed $t$ tests for continuous variables and by both proportionate cancer mortality ratios and Yates-corrected chi squares for categorical variables. Orthopedic surgeons died of cancer more often $\left(\chi^{2}=7.699, P=0.006\right)$ and at younger $(t=5.53, P<0.001)$ ages (mean $=69.4$ years) than general surgeons (mean $=79.2$ years). For site-specific cancers, orthopedic surgeons died of esophageal cancer $\left(\chi^{2}=4.372, P=0.037\right)$ and myeloproliferative malignancies $\left(\chi^{2}=4.369, P=0.037\right)$ more often than general surgeons. Orthopedic surgeons are chronically exposed to MMA and are proportionately more likely to die from cancer, especially esophageal and myeloproliferative cancers, than
\end{abstract}

\section{J. H. Diaz $(\triangle)$}

Environmental and Occupational Health Sciences, School of Public Health, School of Medicine, Louisiana State University, 1615 Poydras Street Suite 1400,

New Orleans, LA 70112, USA

e-mail: jdiaz@1suhsc.edu general surgeons. MMA-exposed healthcare workers may be at increased risks of untimely deaths from site-specific malignancies.

Keywords Methyl methacrylate · Carcinogenicity · Toxicology · Industrial · Occupational · Healthcare industry exposures $\cdot$ Carcinogenic $\cdot$ Toxic

\section{Introduction}

Methyl methacrylate (MMA), a colorless, volatile liquid with an acrid odor, is among the world's most commonly manufactured industrial chemicals with annual world production estimated at 3.2 million tons [1]. With widespread applications in the lighting, painting, paneling, plumbing, sealing, sheeting, and siding industries, and, especially, in the healthcare industry, there is an increasing annual demand for MMA as the world's population ages. The healthcare uses of MMA include dental amalgams and prostheses; orthopedic adhesives and coatings for prosthetic joints; vertebroplasty glues for injection into metastatic and pathologic bone fractures; hearing aids; eyeglass lenses and rims; and the very latest uses in rapidly hardening, acrylic jackets for chest wall reconstruction following radical surgical resections for cancer $[2,3]$. The demand growth for MMA, 3.5\% per year in 2005, is met by the world's largest producers, located in the USA, UK, and Europe [1].

Although ethyl acrylate ingestion has caused dosedependent forestomach carcinomas in rodents and occupational MMA exposures during the 1940s have been associated with excess colorectal cancer mortality in acrylic sheet manufacturing workers, there have been relatively few studies on MMA carcinogenicity in animals or humans $[4,5]$. Most MMA carcinogenicity studies in humans have 
been combined retrospective cohort studies from the 1930s through the 1990s, or meta-analyses of the same and similar studies [4-10]. In addition, most of the negative cancer studies were authored by epidemiologists employed by major chemical manufacturers of MMA in the USA (American Cyanamid Company, Wayne, NJ; Rohm and Hass Co., Croydon, PA) and in the UK (Imperial Chemical Industries; Lucite International UK Ltd.) [6-8].

In light of prior investigations, the purpose of this proportionate cancer mortality study was to achieve the best experimental design, sample size, and statistical power required to identify any existing significant differences in the proportions of cancer deaths in well-matched cohorts of MMA-exposed orthopedic surgeons $(n=468)$ and MMAunexposed general surgeons $(n=1,890)$. The objectives of this investigation were to compare the proportion of deaths during 1991-2001 from both organ system and site-specific cancers in deceased orthopedic surgeons exposed to MMA during joint replacements throughout their careers and in deceased general surgeons not performing joint replacements throughout their careers. Since our control or unexposed population of general surgeons all died before 2000, they were not exposed to the massive MMA releases during newly described MMA-mersilene mesh "sandwich" operations for chest wall reconstruction after radical surgical resections for invasive thoracic malignancies, as this procedure did not enter thoracic surgical practice until later in the twenty-first century [3].

The proportion of cancer deaths in the two comparison cohorts were assumed a priori to be the same, and other, uncontrolled, major behavioral confounders for cancer, including tobacco smoking, smokeless tobacco use, environmental tobacco smoke exposure, ethanol use, dietary saturated fat intake, sedentary lifestyle, activity levels, and lack of exercise, were assumed a priori to have distributed equally between the cohorts of surgeons with similar socioeconomic status and occupational stressors throughout their lifetime careers.

\section{Methods}

Following approval by the Institutional Review Board of the Louisiana State University Health Sciences Center in New Orleans, LA, this proportionate cancer mortality study commenced with requests made to professional association membership directors by officers of the respective associations, the American College of Surgeons (ACS) and the American College of Orthopedic Surgeons (ACOS). All study decedents during the period 1991-2001 were initially identified by their respective professional associations, the ACS and the ACOS, with their names, last addresses, dates of membership, periods of active practice, and dates and places of births and deaths. An initial study sample of 3,458 deceased surgeons, composed of 2,726 general surgeons and 732 orthopedic surgeons, was assembled from professional association membership registries. The subsequent confirmations of deaths by underlying causes were conducted by the National Death Index (NDI), a central, federally operated, computerized data repository of all US deaths; 1979 to the present. The investigators were blinded to the names of decedents confirmed as to underlying causes of death by the NDI.

Stringent exclusion criteria eliminated deaths outside of the US, joint professional association memberships, and several other potential death-related confounders (Table 1). All deaths were confirmed by linkages to state death certificates in states of death with underlying causes of death documented by four-digit ICD-9 codes. Additional exclusion criteria included surgeon deaths in 2000-2001 because all of these deaths had not all been forwarded to the NDI during this study, specifically all of the deaths in the State of New York following the September 11, 2001, terrorist attacks on New York City (Table 1). Female surgeon deaths were also excluded due to the small number of female surgeons dying during the study period, 19912001 (Table 1).

In this proportionate cancer mortality study, only the cancer deaths in professional registry-confirmed orthopedic surgeons were analyzed in comparison to the cancer deaths in professional registry-confirmed general surgeons. The cancer deaths in other operating room (OR) personnel, such as anesthesiologists, nurse anesthetists, and OR nurses, who may have been exposed to MMA vapor during assignments to total joint reconstruction cases were not included in this study.

Table 1 Exclusion criteria applied to the initial death cohort $(N=3,458)$

\begin{tabular}{|c|c|c|c|}
\hline Study cohorts & $\begin{array}{l}\text { General } \\
\text { surgeons }\end{array}$ & $\begin{array}{l}\text { Orthopedic } \\
\text { surgeons }\end{array}$ & Totals \\
\hline Initial sample sizes & 2,726 & 732 & 3,458 \\
\hline \multicolumn{4}{|l|}{ Exclusion criteria } \\
\hline $\begin{array}{l}\text { All deaths in } 20002001 \text {, } \\
\text { except NY }\end{array}$ & 431 & 167 & 598 \\
\hline Foreign deaths & 153 & 11 & 164 \\
\hline New York deaths & 171 & 37 & 208 \\
\hline Female deaths & 4 & 0 & 4 \\
\hline Dual college memberships & 1 & 1 & 2 \\
\hline $\begin{array}{l}\text { Insufficient death information } \\
\text { for NDI confirmation }\end{array}$ & 836 & 49 & 885 \\
\hline $\begin{array}{l}\text { Final NDI matched and } \\
\text { confirmed sample sizes }\end{array}$ & 1,890 & 468 & 2,358 \\
\hline
\end{tabular}

NDI National Death Index 
An a priori power and sample size analysis was conducted before the study subjects were assembled and directed a minimal sample size of 361 decedents in order to achieve $80 \%$ statistical power for correctly identifying significant differences in underlying causes of deaths. The final study sample size included 2,358 deceased surgeons, 1,890 general surgeons and 468 orthopedic surgeons, assumed to have been exposed to MMA vapor during prosthetic joint replacement operations during their professional lifetimes. Following the establishment of the final NDI-matched sample size of 2,358 study subjects, a post hoc power analysis at an alpha significance level of 0.05 demonstrated a statistical power of $98.7 \%$ for chi-square analyses to correctly identify statistically significant proportional differences in cancer deaths, if present.

Continuous variables, including mean ages at death from all causes and mean ages at death from cancer, were tested for statistically significant differences between the MMAexposed orthopedic surgeons and the MMA-unexposed general surgeons by unpaired, two-tailed $t$ tests. Categorical variables including the proportions of deaths from all causes, from organ system-specific cancers and from sitespecific cancers, were tested for statistically significant differences at a significance level of 5\% by Yates-corrected chi-square $\left(\chi^{2}\right)$ analyses. Statistically significant differences for both $t$ tests and the chi squares were indicated by $P$ values equal to or less than 0.05 .

In addition to chi-square comparisons for proportional differences in deaths between the MMA-exposed orthopedic surgeons and the unexposed general surgeons, proportionate cancer mortality ratios (PCMR) were calculated for all cancer deaths, including all-cause cancer deaths, organ systemspecific cancer deaths, and site-specific cancer deaths using the standard formula, $\mathrm{a} / \mathrm{a}+\mathrm{c} / \mathrm{b} / \mathrm{b}+\mathrm{d}$, i.e., the proportion of cancer deaths in the exposed study subjects divided by the proportion of cancer deaths in the unexposed control subjects. As the calculated PCMR approached 1.0, the proportions of cancer deaths in MMA-exposed orthopedic surgeons and unexposed general surgeons approached equality.

\section{Results}

Orthopedic surgeons died at significantly younger ages than general surgeons with mean ages at death of 70.0 years compared to 79.2 years during the study period $(t=16.332$, $P<0.0001$ ) (Table 2). Orthopedic surgeons died of all-cause cancer deaths at significantly younger ages than general surgeons with mean ages at death of 69.4 years compared to 75.2 years $(t=5.530, P<0.001)$ (Table 2). Orthopedic surgeons died of all-cause cancer significantly more often than general surgeons $\left(\chi^{2}=7.699, P=0.006\right)$ and of all hematological malignancies significantly more often than general surgeons $\left(\chi^{2}=7.672, P=0.006\right)$ (Table 3$)$. Orthopedic surgeons died of esophageal cancer $\left(\chi^{2}=4.372\right.$, $P=0.037)$ and of myeloproliferative cancer including multiple myeloma ( $\chi^{2}=4.369, P=0.037$ ) significantly more often than general surgeons (Table 4 ). With the exception of esophageal cancer, there were no differences in the proportions of deaths from all other gastrointestinal malignancies in orthopedic surgeons compared to general surgeons including deaths from cancers of the colon, rectum, small intestine, liver, pancreas, and gall bladder (Table 4). Lastly, with the exception of esophageal cancer, there were no differences in deaths from cigarette smoking, smokeless tobacco, and environmental tobacco smoke exposure-associated malignancies between orthopedic surgeons and general surgeons including cancers of the tracheobronchial tree, lung, stomach, pancreas, colon, rectum, kidney, and bladder (Table 4).

Unlike the assumptions of prior investigations, most tobacco-associated malignancies occurred with equivalent proportions (i.e., proportionate cancer mortality ratios approaching 1.0) in both exposed-case and unexposedcontrol groups, with the exception of esophageal cancer, which has been associated with combined alcohol and tobacco use, reflux esophagitis, Barrett's esophagus, and an absence of Helicobacter pylori seropositivity (Table 4) [11]. Finding no statistically significant differences in most tobacco exposure-associated cancers between orthopedic surgeons and general surgeons confirmed the equivalent circulation of tobacco exposures as potential confounders between MMA-exposed orthopedic surgeons and MMAunexposed general surgeons (Table 4).

\section{Discussion}

Acute and chronic systemic reactions to MMA vapors are relatively common among workers in the healthcare industry and in the acrylic product manufacturing industry. Among healthcare workers, operating room personnel, and dental laboratory technicians, especially those with preexisting asthma, allergies, atopic dermatitis, or reactive airway diseases, appear to be predisposed to acute bronchospasm on new or repeat (Monday morning) MMA exposures [12-21]. These bronchospastic reactions may be accompanied by any combination of cough, oronasal mucosal erythema and edema, dyspnea, generalized erythroderma, and circulatory instability [12-21]. Liquids and pastes of all MMA monomers and polymers can penetrate all types of surgical gloves over time and have caused local dermatological reactions with later lichenification and fissuring in the fingertips of dental laboratory technicians, especially those who choose never to wear gloves at all when molding dental amalgams and dentures [17, 21]. 
Table 2 Mean ages of study cohorts at death $(N=2,458)$

$* P \leq 0.05$, statistically significant

${ }^{\text {a }}$ Two-tailed, unpaired $t$ tests

\begin{tabular}{lcccc}
\hline Mean ages at death & $\begin{array}{l}\text { General surgeons } \\
(n=1,890)\end{array}$ & $\begin{array}{l}\text { Orthopedic surgeons } \\
(n=468)\end{array}$ & $\begin{array}{l}t \text { test values } \\
\text { (unpaired, 2-tailed } t \text { tests })\end{array}$ & $P$ values* \\
\hline $\begin{array}{l}\text { Ages at death, all } \\
\text { causes (years) }\end{array}$ & 79.2 & 70.0 & 16.332 & $\leq 0.0001$ \\
$\begin{array}{l}\text { Ages at death from } \\
\text { cancer, underlying } \\
\text { causes (years) }\end{array}$ & 75.2 & 69.4 & 5.53 & $\leq 0.001$ \\
\hline
\end{tabular}

Chronic workplace exposures to MMA vapors have caused occupational asthma and chronic obstructive airways disease in industrial workers $[15,16]$. The chronic neurotoxic effects of prolonged MMA exposures have been primarily confined to dental laboratory technicians and have included distal sensory peripheral neuropathy, generalized sensory peripheral neuropathy, olfactory dysfunction, and toxic dementia [17-20].

Unlike prior cancer mortality studies of chronic occupational MMA exposures, this investigation was a proportionate cancer mortality study that compared two groups of deceased surgeons assumed a priori to have equivalent all cancer and site-specific cancer mortality (Table 5). All other studies have been retrospective, descriptive, observational studies; standardized mortality rate (SMR) studies comparing observed to expected death rates; or meta-analyses, which have simply lumped prior studies for analysis, including ones by the same authors (Table 5) [4-8]. The design of this study permitted the exact confirmation of professional lifetime occupations and underlying causes of death.

The most important results of this study included the following: (1) Male orthopedic surgeons died from all causes at significantly younger ages than general surgeons. (2) Male orthopedic surgeons died at significantly younger ages from cancer than general surgeons. (3) Male orthopedic surgeons died from esophageal cancer significantly more often than general surgeons. Nevertheless, although the proportion of esophageal cancer deaths remained small in both groups, nine of 1,890 cancer deaths $(0.48 \%)$ in general surgeons versus seven of 468 cancer deaths in orthopedic surgeons $(1.5 \%)$, the difference was statistically significant $\left(\chi^{2}=4.372, P=0.037\right)$. (4) Male orthopedic surgeons died more often from all-cause hematological cancers and site-specific hematological cancers, including myeloproliferative disorders and multiple myeloma, than general surgeons.

Chronic occupational MMA exposures have now been associated with chronic gastritis, achlorohydria, and atrophic and erosive gastritis [22, 23]. Although this study was not designed to analyze the relationships among MMAinduced chronic gastritis, H. pylori seropositivity, and esophageal cancer, chronic occupational MMA exposures can cause chronic atrophic gastritis, and $H$. pylori infection or seropositivity is protective for esophageal cancer $[10,11$, 22, 23]. Therefore, if chronic MMA exposures can destroy acid-producing gastric cells and cause achlorohydric atrophic gastritis, such exposures may also be bactericidal for H. pylori, predisposing MMA-exposed workers to esophageal cancer $[10,11,22,23]$. Nevertheless, the relationships between $H$. pylori infection and gastric atrophy and esophageal cancer cannot be fully explained at this time $[11,22,23]$. Although most gastric carcinomas do indeed arise on a background of atrophic gastritis, there were no significant differences in the proportions of deaths from

Table 3 Proportionate cancer mortality for all cancer deaths and organ system cancer deaths $(N=2,458)$

\begin{tabular}{|c|c|c|c|c|c|}
\hline Cancer deaths & $\begin{array}{l}\text { General surgeons } \\
(n=1,890)\end{array}$ & $\begin{array}{l}\text { Orthopedic surgeons } \\
(n=468)\end{array}$ & $\begin{array}{l}\text { Proportionate } \\
\text { mortality ratios }\end{array}$ & $\begin{array}{l}\text { Chi-square values } \\
\text { (Yates corrected) }\end{array}$ & $P$ values \\
\hline All cancers & 472 & 147 & 1.3992 & 7.699 & $0.006^{*}$ \\
\hline All GI cancers & 75 & 27 & 1.3540 & 2.521 & 0.112 \\
\hline $\begin{array}{l}\text { Upper GI cancers (esophagus, } \\
\text { stomach, SI) }\end{array}$ & 30 & 10 & 1.2652 & 0.390 & 0.533 \\
\hline Colorectal and anal cancers & 45 & 17 & 1.3961 & 1.832 & 0.176 \\
\hline $\begin{array}{l}\text { GB, liver, and pancreatic } \\
\text { cancers }\end{array}$ & 41 & 13 & 1.2178 & 0.379 & 0.538 \\
\hline All GU cancers & 123 & 31 & 1.0151 & 0.0001 & 0.989 \\
\hline All hematological cancers & 128 & 50 & 1.4653 & 7.672 & $0.006^{*}$ \\
\hline
\end{tabular}

$G I$ gastrointestinal, $G B$ gall bladder, $G U$ genitourinary, SI small intestine

$* P \leq 0.050$, statistically significant 
Table 4 Proportionate cancer mortality for all site-specific cancer deaths $(N=2,458)$

\begin{tabular}{|c|c|c|c|c|c|}
\hline Site-specific cancers & $\begin{array}{l}\text { General surgeons } \\
(n=1,890)\end{array}$ & $\begin{array}{l}\text { Orthopedic surgeons } \\
(n=468)\end{array}$ & $\begin{array}{l}\text { Proportionate } \\
\text { mortality ratios }\end{array}$ & $\begin{array}{l}\text { Chi-square values } \\
\text { (Yates corrected) }\end{array}$ & $P$ values \\
\hline Esophageal & 9 & 7 & 2.2232 & 4.372 & $0.037^{*}$ \\
\hline Stomach & 19 & 3 & 0.9884 & 0.217 & 0.642 \\
\hline Small intestine & 2 & 1 & 1.6808 & 0.019 & 0.890 \\
\hline Liver and GB & 13 & 3 & 0.7622 & 0.042 & 0.838 \\
\hline Pancreas & 28 & 10 & 1.3333 & 0.808 & 0.369 \\
\hline Colon & 39 & 15 & 0.0546 & 1.704 & 0.192 \\
\hline Rectum and anus & 6 & 2 & 1.2607 & 0.006 & 0.938 \\
\hline Trachea and lung & 101 & 24 & 0.9658 & 0.005 & 0.943 \\
\hline Prostate & 94 & 21 & 0.9162 & 0.101 & 0.751 \\
\hline Bladder & 14 & 3 & 0.8887 & 0.006 & 0.939 \\
\hline Kidney & 15 & 7 & 1.6128 & 1.313 & 0.252 \\
\hline Thyroid & 4 & 1 & 1.0076 & 0.305 & 0.580 \\
\hline Lymphoma & 64 & 25 & 1.4390 & 3.430 & 0.064 \\
\hline Leukemia & 31 & 9 & 1.1364 & 0.050 & 0.822 \\
\hline Myeloproliferative and multiple myeloma & 33 & 16 & 1.6655 & 4.369 & $0.037 *$ \\
\hline
\end{tabular}

$G B$ gall bladder

$* P \leq 0.050$, statistically significant

gastric carcinoma in MMA-exposed orthopedic surgeons and MMA-unexposed general surgeons, and the proportionate cancer mortality ratio of 0.9884 confirmed that the occurrences of gastric cancer were the same in both groups of surgeons (Table 4) [11, 23, 24].

In addition to the significant increase in deaths in orthopedic surgeons from esophageal cancer, the proportional increase in myeloproliferative cancers in orthopedic surgeons compared to general surgeons, also assumed $a$ priori to be equivalent, cannot be fully explained. However, volatile organic solvents are often used to solubilize lyophilized MMA powders for coating and securing prosthetic joints and have been associated with hematological malignancies following chronic occupational exposures [24].

In addition to its well-established design for studying proportionate deaths from cancer, other strengths of this investigation included its (1) lack of financial sponsorship by major MMA manufacturers, many of whom supported earlier no-excess cancer cohort studies; (2) exact confirmation of death for all study decedents using both professional association and NDI registries; (3) use of four-digit, not three-digit, ICD-9 CPT codes with the highest confirmation $(>80 \%)$, detection $(>80 \%)$, and nosological $(\geq 97 \%)$ match rates for determination of cancer as underlying causes of death based on histopathological diagnoses; and (5) control-to-case ratio of 4:1 using socioeconomically matched general surgeons as controls in similar occupations without MMA exposures and with assumed similar lifestyle cancer risks from alcohol use, diet, and smoking [25-27].

The weaknesses in this investigation that could not be controlled for included (1) all-male study decedents due to the small number of female surgeons $(n=4)$ dying in 19912001; (2) no decedents from New York (NY) State due to unanticipated delays in filing NY State death certificates with the NDI after the September 11, 2001, attacks in New York City; (3) inability to measure the ambient air levels of MMA exposures in deceased orthopedic surgeons over their lifetime professional careers; (4) the relatively small cohort size $(n=468)$ of deceased orthopedic surgeons compared to deceased general surgeons $(n=1,860)$ that, nevertheless, reflected the current professional society membership ratio of approximately $4: 1$; and (5) an inability to account for the interrelationships of protective H. pylori infection or seropositivity, MMA-induced gastric atrophy, and esophageal cancer outcomes in orthopedic surgeons $[11,22,23]$.

\section{Conclusions}

In conclusion, orthopedic surgeons performing total joint reconstructions and re-replacements with currently recommended MMA-cementing techniques died more often of cancer than a well-matched cohort of general surgeons [2830]. The proportionately different cancer deaths in ortho- 


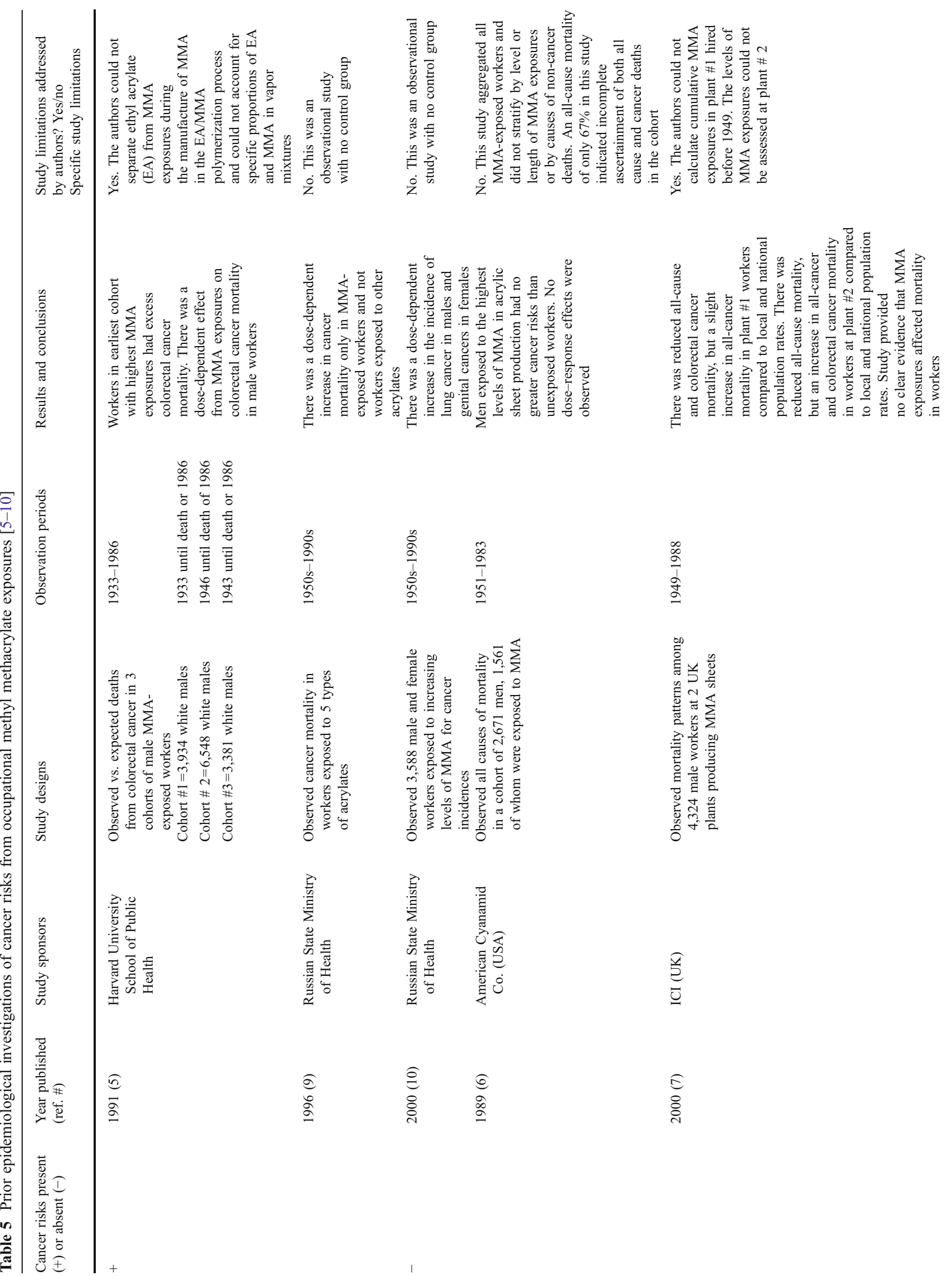




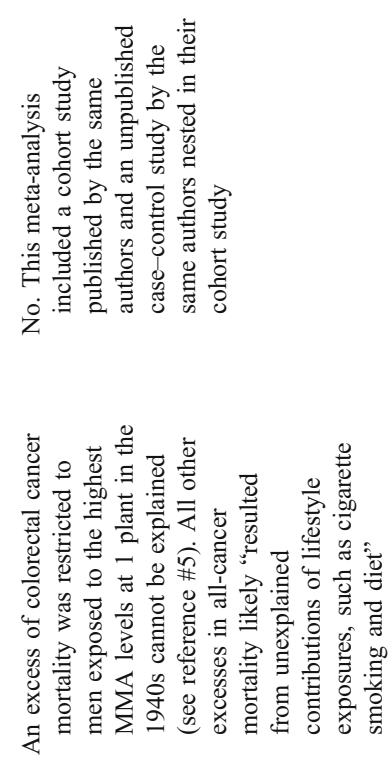

$\overleftrightarrow{z}$

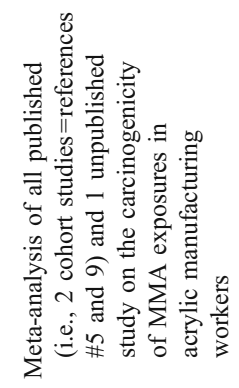

$\frac{\widehat{U}}{2}$

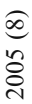

pedic surgeons compared to general surgeons were due to esophageal and myeloproliferative cancers and not to colorectal cancers as in earlier studies (Table 5) $[5,9,10]$. Further investigations will need to be conducted to assess the interrelationships of protective $H$. pylori infection $(<40 \%)$, MMA-induced gastric atrophy, and esophageal cancer outcomes in orthopedic surgeons.

Since some orthopedic surgeons have now adopted selfcontained breathing apparatus (SCBA)-equipped scrub suits for infection control purposes during high-risk intraarticular procedures; such personal protective equipment should also protect them from inhalational MMA exposures, in addition to specially ventilated operating rooms [30]. In the future, general and thoracic surgeons performing chest wall reconstructive procedures with MMA-mersilene mesh "sandwich" prostheses may be at increased risks of MMA exposures and cancer outcomes. Although not federally mandated by regulators in the USA, the periodic measurements of serum or urine methanol concentrations will provide reliable biomarkers for occupational MMA exposures and should be considered for all high-risk exposure groups [31].

Acknowledgments The author gratefully and respectfully acknowledges the assistance and support of many individuals during the prolonged course of this investigation including Robert D'Ambrosia, M.D., FACOS, Past President of the American College of Orthopedic Surgeons, and Former Professor and Chair, Department of Orthopedic Surgery, Louisiana State University Health Sciences Center in New Orleans, LA; J. Patrick O'Leary, M.D., FACS, Former Acting Dean of the School of Medicine and Former Professor and Chair, Department of Surgery, Louisiana State University Health Sciences Center in New Orleans, LA; the dedicated staff of the National Death Index (NDI), National Center for Health Statistics of the United States Centers for Disease Control and Prevention, Hyattsville, MD; and the many medical and masters of public health graduate students (MPH), all now practitioners, who assisted in data collection and early preparation of materials and methods.

Grant support This investigation was supported only by an initial competitive seed grant from the Dean's Research Grant Program, Office of the Dean, Louisiana State University Health Sciences Center in New Orleans, LA, and all grant funds $(\$ 12,500)$ were applied to all fees for the NDI Plus death confirmation searches for 3,458 deaths $(\$ 12,500$ at the time).

Disclosures Incompletely analyzed portions of this investigation were previously presented at the Second National Environmental Public Health Conference sponsored jointly by the Agency for Toxic Substances and Disease Registry (ATSDR) and the United States Centers for Disease Control and Prevention (CDC) in Atlanta, GA, on October 28, 2009; and as a Poster Presentation for Previously Presented Research Investigations at the 2010 Annual Spring Meeting of the American College of Medical Toxicology in Scottsdale, AZ, on March 12-14, 2010.

The sole author of this original research article has no financial or any other conflicts of interest to disclose. 


\section{References}

1. The Innovation Group. Methyl methacrylate chemical profile (3 Jan 2004). Available at http://www.the-innovation-group.com/ ChemProfiles/Methy20\%Methacrylate.htm

2. Rosa MA, Maccauro G, Sgambato A et al (2003) Acrylic cement added with antiblastics in the treatment of bone metastases. Ultrastructural and in vitro analysis. J Bone Joint Surg 85:712-716

3. Fouad FA (2006) Chest wall resection and reconstruction: analysis of 11 cases after methylmethacrylate reconstruction. J Egypt Natl Cancer Inst 18:175-182

4. Ghanayem BI, Sanchez IM, Maronpot RR, Elwell MR, Matthews HB (1993) Relationship between the time of sustained ethyl acrylate forestomach hyperplasia and carcinogenicity. Environ Health Perspect 101(Supp 5):277-279

5. Walker AM, Cohen AJ, Loughlin JE, Rothman KJ, DeFonso LR (1991) Mortality from cancer of the colon or rectum among workers exposed to ethyl acrylate or methyl methacrylate. Scand J Work Environ Health 17:7-19

6. Collins JJ, Page LC, Caporossi JC, Utidjian HM, Saipher JN (1989) Mortality patterns among men exposed to methyl methacrylate. J Occup Med 31:41-46

7. Tomenson JA, Bonner SM, Edwards JC et al (2000) Study of two cohorts of workers exposed to methyl methacrylate in acrylic sheet production. J Occup Environ Med 57:810-817

8. Tomenson JA, Carpenter AV, Pemberton MA (2005) Critical review of the epidemiology literature on the potential cancer risks of methyl methacrylate. Int Arch Occup Environ Health 78:603-612

9. Geiko OI, Fedotova IV, Blagodatin VM (1996) Epidemiologichygienic aspects of the assessment of carcinogenic risk in methacrylate production. Med Tr I Prom Ekol 2:4-7

10. Fedotova IV, Litovskaia AV, Egorova IV, Oskerko EF, Shal'nova VA (2000) Specific features of adverse effects in workers exposed to different levels of methylmethacrylate. Gig Sanit 5:26-29

11. Anderson LA, Murphy SJ, Johnston BT et al (2008) Relationship between Helicobacter pylori infection and gastric atrophy and the stages of oesophageal inflammation, metaplasia, adenocarcinoma sequence: results from the FINBAR case-control study. Gut 57:721-723

12. Scolnick B, Collins J (1986) Systemic reaction to methyl methacrylate in an operating room nurse. J Occup Med 28:196-198

13. Kirby BS, Doyle A, Gilula LA (2003) Acute bronchospasm due to exposure to polymethylmethacrylate vapors during percutaneous vertebroplasty. Am J Radiol 180:543-544

14. Wittczak T, Palczynski C, Sculc B, Gorski P (1996) Bronchial asthma with inflammation of the nose mucous membrane induced by occupational exposure to methyl methacrylate in a dental technician. Med Pr 47:259-266
15. Lozewicz S, Davison AG, Hopkirk A et al (1985) Occupational asthma due to methyl methacrylate and cyanoacrylates. Thorax 40:836-839

16. Marez T, Edme JL, Boulenguez C, Shirali P, Haguenoer JM (1993) Bronchial symptoms and respiratory function in workers exposed to methylmethacrylate. Br J Ind Med 50:894-897

17. Leggat PA, Kedjarune U, Smith DR (2004) toxicity of cyanoacrylate adhesives and their occupational impacts for dental staff. Ind Health 42:204-211

18. Seppalainen AM, Rajaniemi R (1984) Local neurotoxicity of methyl methacrylate among dental technicians. Am J Ind Med 5:471-477

19. Sadoh DR, Sharief MK, Howard RS (1999) Occupational exposure to methyl methacrylate monomer induces generalized neuropathy in a dental technician. Br Dent J 186:380-381

20. Prescott E, Steendahl U, Damsgaard MT (1989) Organic dementia among dental technicians. A cross-sectional study of dental technicians with optitians as the control group. Ugeskr Laeger 151:1868-1871

21. Lönnroth E-C (2003) Resistance of medical gloves to permeation by methyl methacrylate (MMA), ethylene glycol dimethacrylate (EGDMA), and 1, 4-butanediol dimethacrylate (1, 4-BDMA). Int J Occup Saf Ergon 9:289-299

22. El-Zimaity H (2008) Gastritis and gastric atrophy. Curr Opin Gastroenterol 24:682-686

23. Sharova TG (1989) Chronic gastritis in patients with methylmethacrylate poisoning. Gig Tr Prof Zabol 3:12-16

24. Scherr PA, Mueller NE (1521) Non-Hodgkin's lymphomas. In: Schottenfeld D, Fraumani JF Jr (eds) Cancer epidemiology and prevention, 2nd edn. Oxford University Press, New York, p 1521

25. Nelson DE, Swanson GM, Schwartz AG, Brix K, Fine LJ (1987) Occupation and industry data obtained from death certificates: the effect and influence of case selection. J Occup Med 29:52-56

26. Dubrow R, Sestito JP, Lalich NR, Burnett JA, Saly JA (1987) Death certificate-based occupational mortality surveillance in the United States. Am J Ind Med 11:329-342

27. Wacholder S, Silverman DT, McLaughlin DT, Mandel JS (1992) Selection of controls in case-control studies. III. Design options. Am J Epidemiol 35:1042-1050

28. Harris WH (1995) The case for cementing all femoral components in total hip replacement. Can J Surg 38:S55-S60

29. Davis CM III, Berry DJ, Harmsen WS (2003) Cemented revision of failed uncemented femoral components of total hip arthroplasty. J Bone Joint Surg 85:1264-1269

30. Gallo J, Landor I, Vavrik P (2006) Current strategies for prevention of prosthetic joint infection. Acta Chir Orthop Traumatol Cech 73:229-236

31. Mizunuma K, Kawai T, Yasugi T et al (1993) Biological monitoring and possible health effects in workers occupationally exposed to methyl methacrylate. Int Arch Occup Environ Health $65: 227-232$ 